\title{
A Study of Tropical Cyclone Motion with a Nested-Grid Model Including Rainwater Prediction
}

\author{
by \\ Masanori Yamasaki \\ Meteorological Research Institute, Tsukuba, Ibaraki, 305 Japan \\ (Received March 26, 1992 ; Revised July 6, 1992)
}

\begin{abstract}
Numerical experiments of tropical cyclone motion are performed with the use of a triply-nested grid model which has been developed primarily for the study of tropical cyclones. One of the features of the model is that the mixing ratios of cloud water and rainwater are taken to be predicted variables because evaporation of rainwater and convective downdraft are considered to be important. Cumulus parameterization and other aspects of the model are basically the same as those described in Yamasaki $(1986,1987)$ except for the use of the longitude-latitude coordinates, inclusion of topography, finer vertical resolution (ten-layer model) and so on. The grid sizes of the coarse, intermediate and fine grid areas are taken to be $15 / 4,5 / 4$ and 5/12 degrees, respectively .

Several typhoons in August and September 1990 (SPECTRUM period) are chosen for the numerical experiments. The initial condition is taken from the objectively analyzed global data of JMA. An axially symmetric vortex is superimposed on this data. The objective of this study is to see to what degree the model can predict typhoon motion and what are the primary causes of prediction errors. It is found that while the model appears to show somewhat good performance for the prediction of typhoon motion, the primary causes of prediction errors are poor prediction of the behavior of the subtropical high and the initial fields of wind and conditional instability.
\end{abstract}

\section{Introduction}

Tropical cyclone motion forecast is one of the most important problems in meteorology. In recent years significant advances have been made in forecast accuracy, which is largely due to developments and improvements of numerical prediction models as well as advances in observation. The accuracy of predicted motion from numerical models is generally better than that from statistical and other methods for time periods beyond about 24 hours. In spite of such advances in numeri-

(C) 1992 by the Meteorological Research Institute cal prediction, however, its accuracy is not satisfactory yet (see e.g., Ueno, 1991a, b; Iwasaki and Ueno, 1991). This is partly because observational data is neither dense nor good enough to give an initial condition which is adequate for the numerical prediction model, and partly because the present numerical models are not necessarily representative of atmospheric processes, particularly with respect to motions greatly affected by subgridscale motions such as cumulus convection and boundary layer processes.

Another cause of prediction errors comes from initialization problem as to how observational data should be processed. Our inade- 
quate understanding of the mechanism of tropical cyclone motion is also responsible for the present level of prediction accuracy. Improvements in numerical models and initialization techniques will be achieved if we can understand the mechanism of tropical cyclones well and clarify what meteorological variables are the more important in tropical cyclone motion.

Although the importance of the problem of tropical cyclone motion has been strongly recognized, more studies have been directed toward the problems of tropical cyclone formation, development and structure over the last three decades. In recent years, however, the Office of the Naval Research has made an intensive study of tropical cyclone motion: ONR five-year Research Initiative (1986-1991) (Elsberry, 1988) and produced many results in its basic research (Elsberry and Abbey, 1991). A special observation called TCM-90 was also carried out in August and September 1990 (Elsberry et al., 1990). In response to this, other special observations called SPECTRUM (Special Experiment Concerning Typhoon Recurvature and Unusual Movement) and Typhoon-90 were conducted by the member countries (Japan and others) of the ESCAP/ WMO Typhoon Committee and by USSR, respectively. Two technical conferences on SPECTRUM were held in 1990 and 1991. These have encouraged studies on tropical cyclone motion in the past five years.

There are many factors which may contribute to tropical cyclone motion. It is well known that tropical cyclones move, as a first approximation, by the effect of advection due to the large-scale environmental flow. The so-called 'steering' concept has been useful to predict and understand the motion of observed tropical cyclones. The large-scale environmental flow, however, is not uniform in most cases, and it is sometimes difficult or not necessarily possible to define a steering flow when the environmental flow has vertical and/ or horizontal shear. Another difficult problem is that the environmental flow itself changes with time, and therefore, its adequate prediction is indispensable to good prediction of tropi- cal cyclone motion. This is probably one of the most important factors which cause errors of predicted motion, particularly for predictions longer than one or two days.

Even in the case in which the environmental flow is uniform, tropical cyclone motion deviates from the steering flow owing to various causes. For instance, when two tropical cyclones exist at a somewhat short distance in a uniform flow, they may interact upon each other and are not steered simply by the flow. Another example is the so-called beta drift (e. g., Holland, 1983, 1984). That is, a tropical cyclone tends to move northwestward relative to a uniform flow because the Coriolis parameter varies with latitude. The importance of the internal structure of tropical cyclones to the beta drift has been studied by many researchers (e.g., Ohnishi and Yamasaki, 1982; Ohnishi, 1989, 1991; Fiorino and Elsberry, 1989a, b; Kamahori, 1991).

Another cause of the departure of tropical cyclone motion from the steering flow is related to the dynamics of a vortex which results from its asymmetric structure (Yamasaki and Ohnishi, 1985; Ohnishi, 1989). This happens even when the Coriolis parameter is assumed to be constant, provided that asymmetry is produced by some causes such as non-uniform sea surface temperature and atmospheric conditions. This is probably one of the most important mechanisms in the meandering, trochoidal or irregular motion of tropical cyclones.

It is also known that horizontal convergence often plays a significant role in tropical cyclone motion. Horizontal convergence is induced by the vertical shear of the large-scale flow and by diabatic heating primarily due to convective activity. These processes affect tropical cyclone motion directly, and are also responsible for asymmetric structure of tropical cyclones, which may cause the motion of the type mentioned above.

This paper describes some results from studies of tropical cyclone motion in the MRI (Meteorological Research Institute of JMA), with the use of a three-dimensional model which has been designed to simulate the mech- 
anisms of tropical cyclone motion. Some of the important requirements for the model are that large-scale environmental flow and disturbances (subtropical high, mid-latitude disturbances in the westerlies and so on) be treated over a long period of time (more than three days) and that internal structure of tropical cyclones be described well with a fine resolution. For this purpose, a nested-grid model has been developed. This technique of the nested grids has been used by many researchers of tropical cyclones (e.g., Ookochi, 1974; Mathur, 1974; Madala and Piacsek, 1975; Ley and Elsberry, 1976; Kurihara and Bender, 1980, 1982; Harrison, 1981; Harrison and Fiorino, 1982) and also used in the earlier version of the JMA typhoon model (Ookochi, 1978) called the moving multiple-nested grid model (MNG), which was used as an operational model for several years beginning in 1982. The structure of tropical cyclones can be described well by the fine grid of the nested grid system.

Even with a fine grid, individual convective clouds in tropical cyclones cannot be treated. Parameterization of cumulus-scale motion is very important because heating distribution determines tropical cyclone structure and therefore, affects tropical cyclone motion significantly. A parameterization scheme described in Yamasaki $(1986,1987)$ is used in this study. The scheme was devised based on an understanding of the mechanism of mesoscale organization of convection in tropical cyclones (Yamasaki, 1983). Since cooling due to evaporation of rainwater and convective downdraft play important roles, the mixing ratios of cloud water and rainwater are taken to be predicted variables. This is one of important features of the present model.

In this study, however, it is not discussed what differences are produced by different parameterization schemes in the problem of tropical cyclone motion. This will be left for future studies. The primary objectives of this study are to see to what degree the present model can predict tropical cyclone motion and to find what are the primary causes of prediction errors.

Typhoons treated are T9010 (Vernon),
T9011 (Winona), T9012 (Yancy), T9014 (Zola), T9015 (Abe), T9018 (Ed), T9019 (Flo) and T9020 (Gene) among the 11 typhoons in August and September 1990 when SPECTRUM and TCM-90 were conducted. Initial data used are the objectively analyzed global data of JMA. It is expected that many studies with the use of SPECTRUM and TCM90 data will be made in coming years. This is a preliminary study, which should be compared with such future studies. This study is hopefully a step toward better understanding of the mechanism of tropical cyclone motion.

\section{Outline of the model}

The model used in this study is basically the same as the triply-nested grid model described in Yamasaki (1986, 1987) except for the use of the longitude-latitude coordinates, inclusion of topography, finer vertical resolution (ten-layer model) and so on*.

The equations of motion in the longitudinal and latitudinal directions may be written, with sigma $\sigma$ as the vertical coordinate, as follows:

$$
\begin{aligned}
& \frac{d u}{d t}-\left(f+\frac{u \tan \varphi}{a}\right) v \\
& =-Z \frac{\partial p_{s}}{a \cos \varphi \partial \lambda}-\frac{\partial \phi}{a \cos \varphi \partial \lambda}+F(u) \\
& \frac{d v}{d t}+\left(f+\frac{u \tan \varphi}{a}\right) u \\
& =-Z \frac{\partial p_{s}}{a \partial \varphi}-\frac{\partial \phi}{a \partial \varphi}+F(v)
\end{aligned}
$$

where

$$
\frac{d}{d t} \equiv \frac{\partial}{\partial t}+u \frac{\partial}{a \cos \varphi \partial \lambda}+v \frac{\partial}{a \partial \varphi}+W \frac{\partial}{\partial \sigma},
$$

* An eight-layer version of the model was used for the study of several typhoons in 1987, and results were presented at the 18th Conference on Hurricanes and Tropical Meteorology (Yamasaki, 1989) and at the Symposium of the Meteorological Society of Japan in November 1989 (Yamasaki, 1990). 


$$
\begin{aligned}
& W \equiv \frac{d \sigma}{d t}, \\
& Z \equiv \sigma R T / p, \\
& f=2 \Omega \sin \varphi .
\end{aligned}
$$

The notations are $t$ : time, $\lambda$ : longitude, $\varphi$ : latitude, $u$ : zonal velocity, $v$ : meridional velocity, $W$ : vertical $\sigma$-velocity, $p$ : pressure, $p_{S}$ : surface pressure, $\phi$ : geopotential, $T$ : temperature, $f$ : Coriolis parameter, $a$ : radius of the earth, $\Omega$ : angular velocity of the earth's rotation and $R$ : gas constant. The last terms $F(u)$ and $F(v)$ are the eddy viscosity.

The equation of continuity and the hydrostatic equation are

$$
\begin{aligned}
-\frac{\partial p_{s}}{\partial t}+\frac{\partial(u \pi)}{a \cos \varphi \partial \lambda}+ & \frac{\partial(v \cos \varphi \pi)}{a \cos \varphi \partial \varphi} \\
& +\frac{\partial(W \pi)}{\partial \sigma}=0 \\
\frac{\partial \phi}{\partial \sigma}= & -\frac{R T}{p} \pi
\end{aligned}
$$

where

$$
\pi \equiv p_{S}-p_{T}
$$

and $p_{T}$ is the pressure of the top of the domain under consideration, which is taken to be 100 $\mathrm{mb}$ in this study.

The thermodynamic equations and equations for the mixing ratios of water vapor, cloud water and rainwater are similar to those in Yamasaki (1986) except that $\partial / \partial x$ is replaced by $(1 / a \cos \varphi)(\partial / \partial \lambda)$ and $\partial / \partial y$ by $(1 / a)(\partial / \partial \varphi)$. As for these equations and the parameterization scheme, the readers are referred to Yamasaki $(1986,1987)$. (The continuity equation was misprinted in those papers so that $p_{S}$ should be replaced by $\pi$.)

The vertical structure of the numerical model used in this study is similar to Fig. 1 of Yamasaki (1986) except that the number of the layers, where the horizontal velocities and the geopotential are predicted, is taken to be 10 . The values of $\sigma$ at levels where the vertical $\sigma$-velocity $W$ is defined are specified by

$$
\sigma_{\ell}=\frac{\bar{p}_{\ell}-p_{T}}{p_{0}-p_{T}} \quad(\ell=1,2, \cdots, 11),
$$

where $p_{0}$ is $1010 \mathrm{mb}$ and $\bar{p}_{\ell}(\ell=1,2, \cdots, 11)$ are taken to be $100,150,200,280,400,550$, $700,820,900,955$ and $1010 \mathrm{mb}$, respectively. The earth's surface corresponds to $\sigma=1$ and the top of the atmosphere under consideration to $\sigma=0$. The pressure at $\sigma_{\ell}$ can be determined from

$$
p_{\ell}=\sigma_{\ell}\left(p_{S}-p_{T}\right)+p_{T} .
$$

The geopotential at the surface is given by $\phi_{S} \equiv g H$, where $H$ is the height of the earth's surface $(H \geqq 0)$ and $g$ is the acceleration of gravity. The geopotential $\phi_{\ell}(\ell=10,9, \cdots, 1)$ are determined from the hydrostatic equation (4) with the lower boundary condition $\phi=\phi_{S}$ at $\sigma=1$.

The grid sizes of the coarse, intermediate and fine grid areas are taken to be $15 / 4,5 / 4$ and $5 / 12$ degrees, respectively, in the longitude-latitude coordinates. (The ratio of the grid sizes is 3.) The coarse grid area has been designed to cover the global area. However, in order to save computer time, only the area north of 30 degrees south latitude $(30 \mathrm{~S})$ is treated in the present study. The coarse grid area includes the north pole. In order to avoid computational instability for a given time increment, some average is made for dependent variables at high-latitude areas near the north pole. The intermediate grid covers the area from $60 \mathrm{~N}$ to $15 \mathrm{~S}$ and from $90 \mathrm{E}$ to $180 \mathrm{E}$. The fine grid area is specified, depending on the position and anticipated track of the typhoon treated. The size of the fine grid area is taken to be 30 degrees longitude and 25 degrees latitude wide in all the cases in this study. The numbers of the grid points of the coarse, intermediate and fine grid areas are $96 \times 32,72 \times 60$ and $72 \times 60$, respectively. A time increment $\Delta t$ is chosen to be 40 seconds.

The initial condition is taken from the global analysis data of JMA. The data is given on a grid of 1.875 degrees. As for the vertical direction, the data is given at the surface, 850 , $700,500,400,300,250,200,150$ and $100 \mathrm{mb}$. These grid data are interpolated so as to give 
data at grid points of the present model. Since the typhoon given by the global analysis data is usually significantly weak compared with observed typhoons, an axially symmetric vortex is superimposed on this data. The specifications of the wind field of the superimposed vortex are based on the observed intensity (but still weaker) and size of the typhoon. According to numerical experiments, however, such superposition of a vortex on the original data does not have much effect on the predicted typhoon movement. (This does not mean that the initial condition for a vortex is not important to its predicted motion. This should depend on how and to what degree the initial condition is changed as well as on the characteristics of the model used.)

A pre-processing method has been used in many operational forecast models; that is, the observed motion of a typhoon has been used to modify the initial environmental flow in the vicinity of the typhoon (Shewchuk and Elsberry, 1978). This technique is not used in this study simply because it is intended, as a first step of the study, to see the result obtained without such modification.

As mentioned in section 1 , typhoons treated in this study are 8 typhoons in August and September 1990. By using different initial date for each typhoon, about twenty numerical experiments are made with time integration periods of $2 \sim 5$ days. It will be suggested that the primary causes of errors in typhoon motion prediction are poor prediction of the behavior of the subtropical high and the initial fields of wind and conditional instability.

\section{Results}

Fig. 1 shows the result for T9010 (Vernon). The solid line with black circles indicates the best track and the circles are the positions of the typhoon at August 1, 2, 3, 4, 5 and $6,00 \mathrm{UTC}$, as indicated by the numerals. The lines with open circles show predicted tracks and positions. Three predictions are made with data of Aug. 1, 2 and 3,00UTC.

As seen in this figure, T9010 moved northward till Aug. 4 and turned in the east-north- east direction afterwards. Although predictions are not bad for initial data of Aug. 2 and 3 , the predicted movement for Aug. 1 is inclined further eastward than the actual course taken. The position error at 96 hour prediction is about $500 \mathrm{~km}$.

The prediction error of the early northeastward turning mentioned above is related to poor prediction of the northward extension of a subtropical high, which took place during Aug. 1 3. Fig. 2 shows the geopotential height at $700 \mathrm{mb}$ at Aug. 1 and 3, 00UTC, which is based on the global analysis data of JMA. As indicated by the contour of $316 \times 10^{2}$ $\mathrm{m}^{2} \mathrm{~s}^{-2}$, the subtropical high was intensified and extended northward from Aug. 1 till Aug. 3. This may be partly related to the eastward movement of a mid-latitude high (about $37 \mathrm{~N}$ ), which was associated with the large-scale wave disturbances in the westerlies. The northward extension of the subtropical high is not predicted well by the model. Fig. 3 shows the predicted $700 \mathrm{mb}$ geopotential at 24 hours (2 Aug.). This figure is made by an interpolation of the geopotential predicted at $625 \mathrm{mb}$ and that at $760 \mathrm{mb}$ in the model. (The values of the $700 \mathrm{mb}$

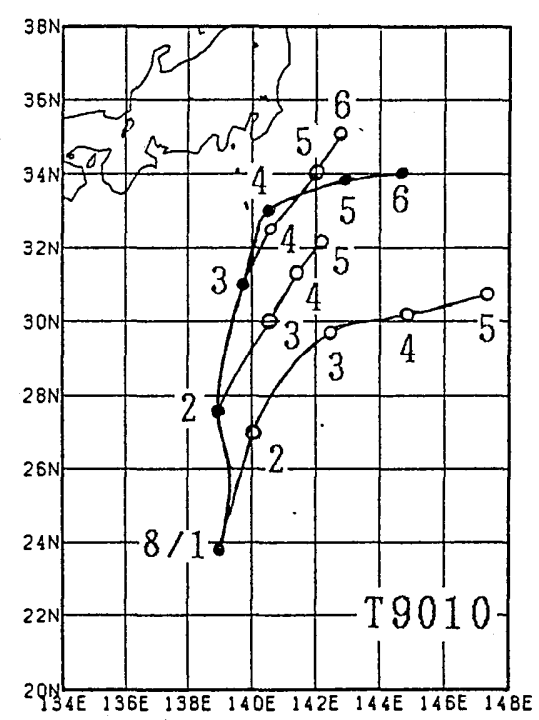

Fig. 1 Best track and positions of T9010 (lines with black circles) and predicted ones (with open circles). Initial time is 00 UTC, Aug. 1, 2 and 3. 


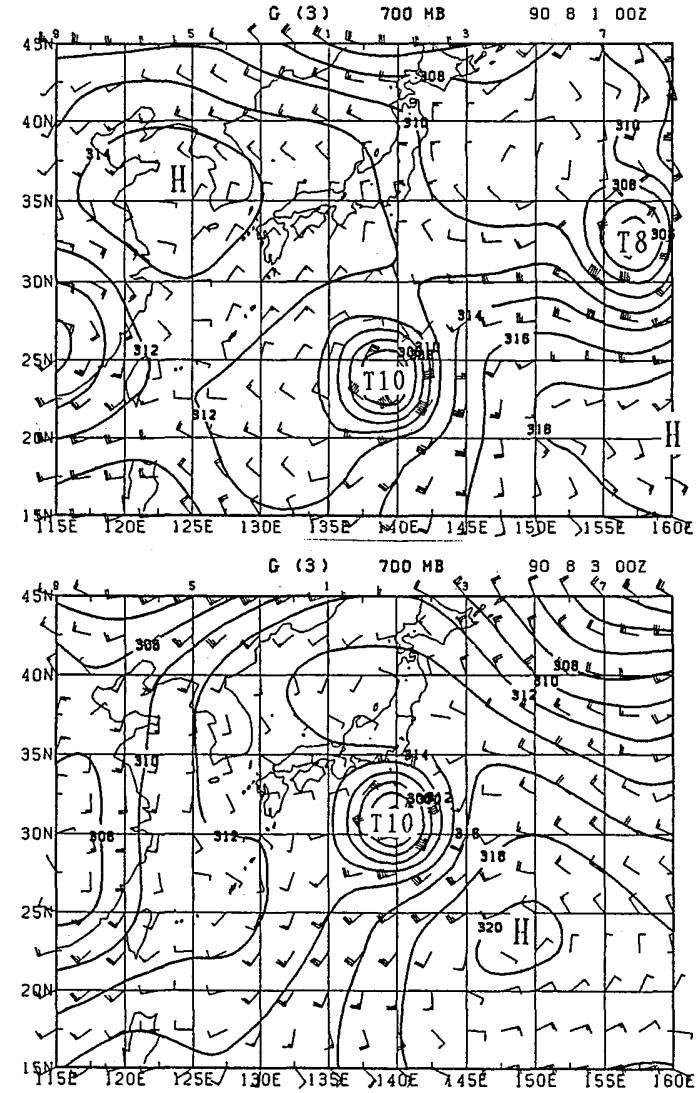

Fig. 2 The $700 \mathrm{mb}$ geopotential height (unit: $10^{2} \mathrm{~m}^{2} \mathrm{~s}^{-2}$ ) and wind fields made from the global analysis data at 00UTC, Aug. 1 and 3 .

geopotential are slightly smaller in the model than those of the analysis data even at the initial time. This is related to interpolation used in the conversion between the analysis data and the model grid data.) Although the northwestward extension of the high is simulated to some extent, it is not sufficiently good. The extension is most pronounced at 36 hours, becoming weak afterwards. The high tends to extend rather westward to the south of the typhoon, which is the cause of the eastward turning. This feature is qualitatively in agreement with the observed.

Fig. 4 shows the result for T9011 (Winona), and Fig. 5 shows the $700 \mathrm{mb}$ geopotential at 00UTC, Aug. 7 and Aug. 9.

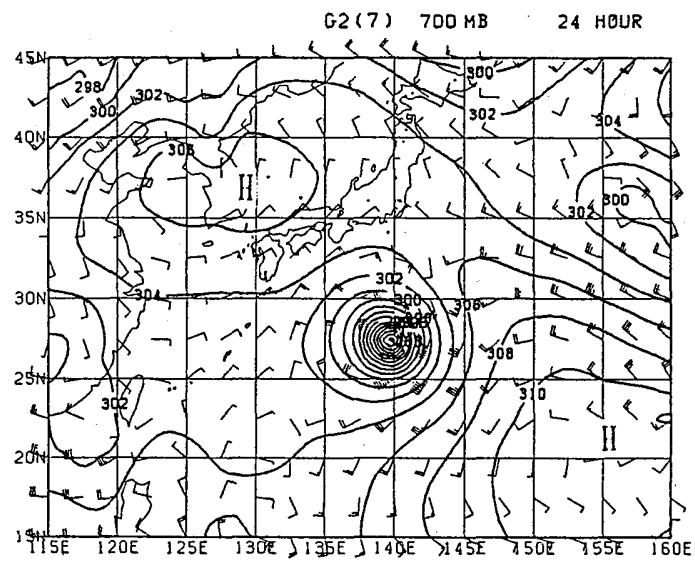

Fig. 3 The predicted $700 \mathrm{mb}$ geopotential at 24 hours for the initial data of 00UTC, 1 Aug.

On Aug. 7, a tropical depression TD was located to the southwest of T9010 and became T9011 on Aug. 8. A subtropical high penetrated between the two typhoons. The northwestward penetration of the subtropical high seemed to be related to an eastward moving mid-latitude ridge, as in the case of T9010.

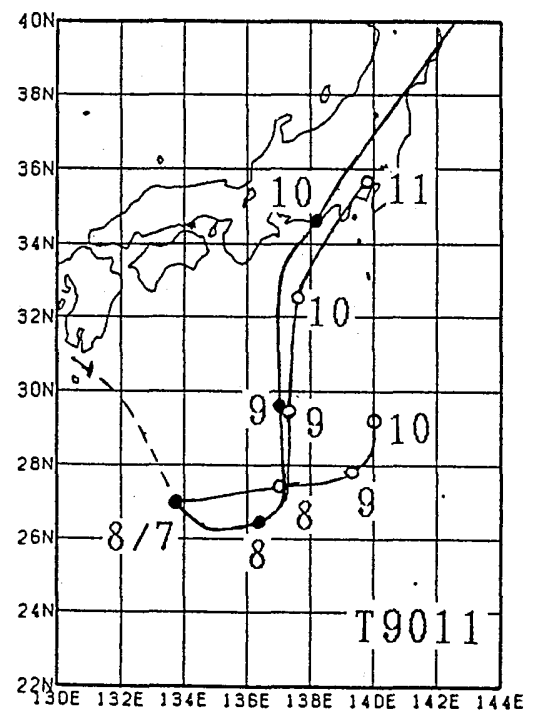

Fig. 4 Best track and predicted ones of T9011. Initial time is 00UTC, Aug. 7 and 8. 



Fig. 5 The $700 \mathrm{mb}$ geopotential height and wind fields at 00UTC, Aug. 7 and 9.

The model does not predict well this behavior of the subtropical high and therefore, the prediction of $\mathrm{T} 9011$ is very bad when the initial data of Aug. 7, 00UTC is used. The northward turning of the typhoon is delayed by one day, and the northward movement is too slow. For Aug. 8 data, the track prediction is somewhat good for the first 36 hours. This is due to good prediction of the northwestward extension of the subtropical high. The initial and 24-hour predicted fields are shown in Fig. 6. After 24 hours, however, the predicted movement is slower than the actual speed. The landfall on the Japan Islands was 00UTC, 10 August, while the predicted one is 14UTC. The typhoon continued to accelerate. According to the analysis data, the ridge in the middle latitudes moved eastward, and the subtropical high
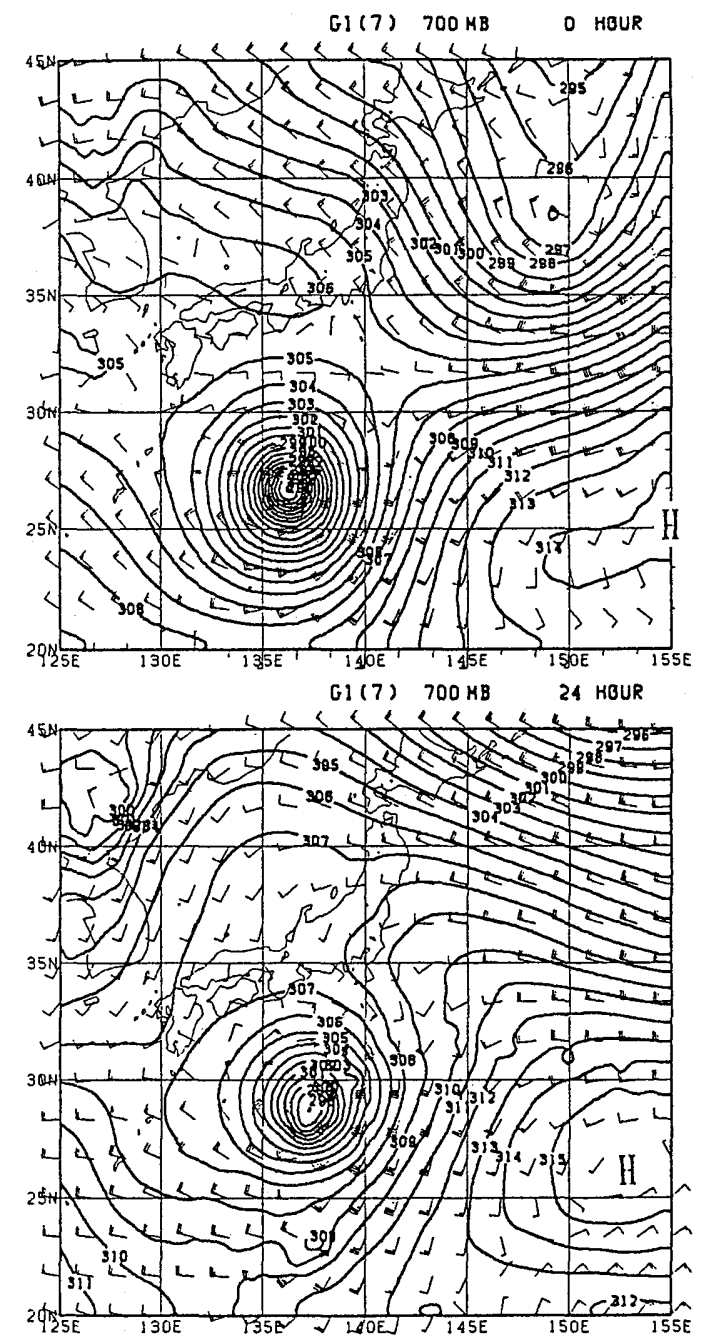

Fig. 6 The $700 \mathrm{mb}$ geopotential at the initial time (00UTC, 8 Aug.) and 24-hour predicted geopotential field. Only the fine grid area is shown.

extended further northward on Aug. 10 (not shown). A southerly flow was intensified to the east of the typhoon. These caused the acceleration of the typhoon movement. The model, however, did not predict well such intensification of the southerly flow.

Fig. 7 shows the result for T9012 (Yancy), and Fig. 8 the $700 \mathrm{mb}$ geopotential at 00UTC, Aug. 16 and 19. This typhoon had a relatively large size and made small-scale irregular movement. When the Aug. 16 data is 
used, the predicted typhoon moves northwestward, and the moving distance for the first 24 hours is only about $200 \mathrm{~km}$. That is, the westward component of the predicted movement is very small. These errors of the predicted direction and speed seem to be due to the initial condition of the wind field. According to the wind velocity field at $700 \mathrm{mb}$ estimated from the global analysis data (Fig. 9), the maximum wind velocity is located to the southeast of the typhoon center. The wind velocity inside the $500 \mathrm{~km}$ radius from the center is also stronger to the south than to the north, although another area of strong winds is found in the southwestern periphery $(27 \mathrm{~N}, 138 \mathrm{E})$ of the subtropical high. The slow westward movement may be related to this feature of the wind field. It appears that the environmental easterly flow is almost absent initially and that the typhoon moves primarily by the beta drift in the model. This is a typical example in which it is necessary for the initial wind field to be adjusted so as to be consistent with the actual initial movement. It is also seen from Fig. 7 that an abrupt turning which took place around 12UTC, Aug. 17 is not predicted for the initial data of 00UTC, Aug. 17, although the predicted movement is roughly in agreement with the observed.

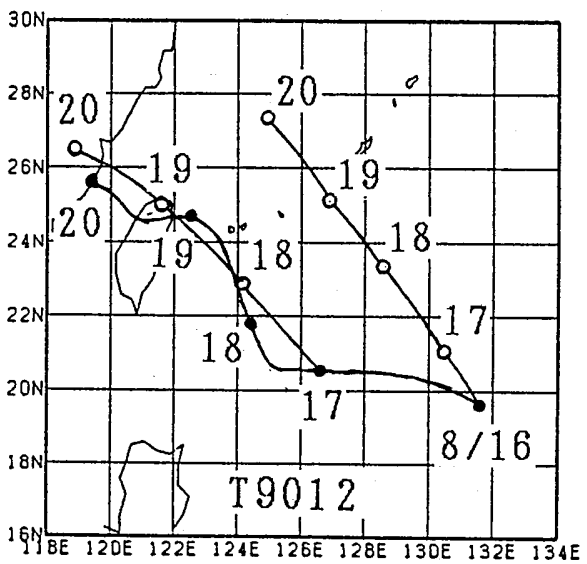

Fig. 7 Best track and predicted ones of T9012. Initial time is 00UTC Aug. 16 and 17.
Fig. 10 shows the result for T9014 (Zola). On Aug. 16, the typhoon was still at the genesis stage, and it was not clearly identified on the $700 \mathrm{mb}$ geopotential field of Fig. 8. After its formation on Aug. 18, the typhoon continued to move northward till Aug. 19, and turned northwestward afterwards. The model simulates the formation of the typhoon and the northwestward turning on Aug. 19 successfully, although the location is not predicted well. When the 00UTC, Aug. 20 data is used, the predicted movement is too slow. For the 12 UTC, Aug. 20 data (triangle indicates positions at 12UTC), the 36 -hour prediction (00 UTC, Aug. 22) is good. However, the acceleration of the movement which took place afterwards is not simulated. A subtropical high
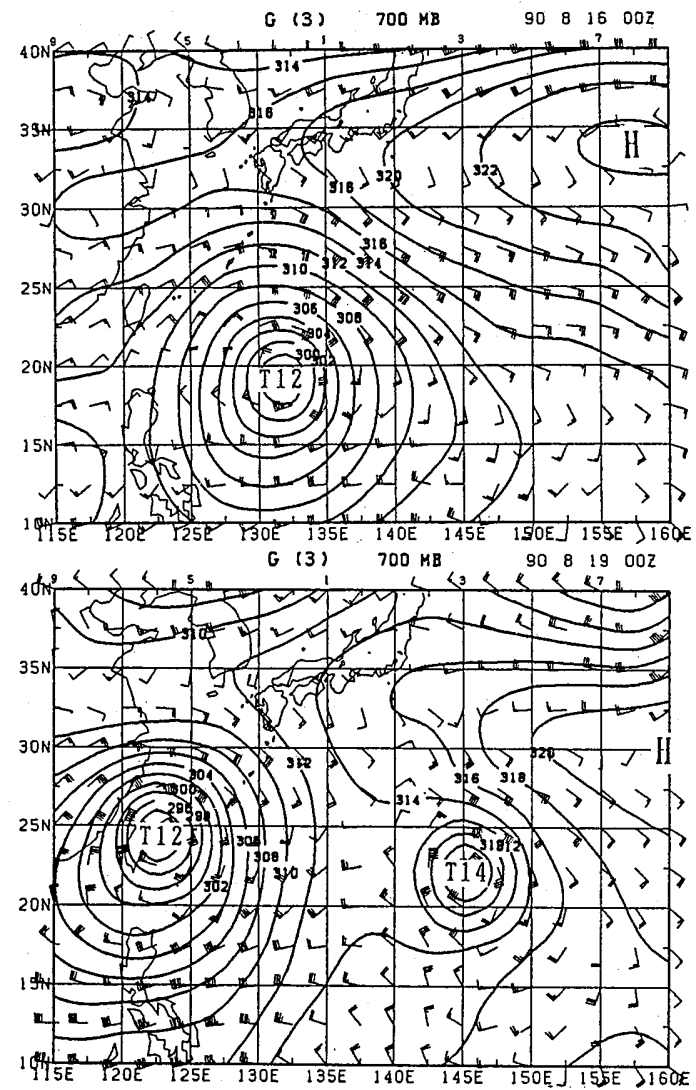

Fig. 8 The $700 \mathrm{mb}$ geopotential height and wind fields at 00UTC, Aug. 16 and 19. T9014 is located to the east of T9012 in the lower figure. 
VEL (3) $\quad 700 \mathrm{~KB} \quad 90 \quad 8 \quad 16007$

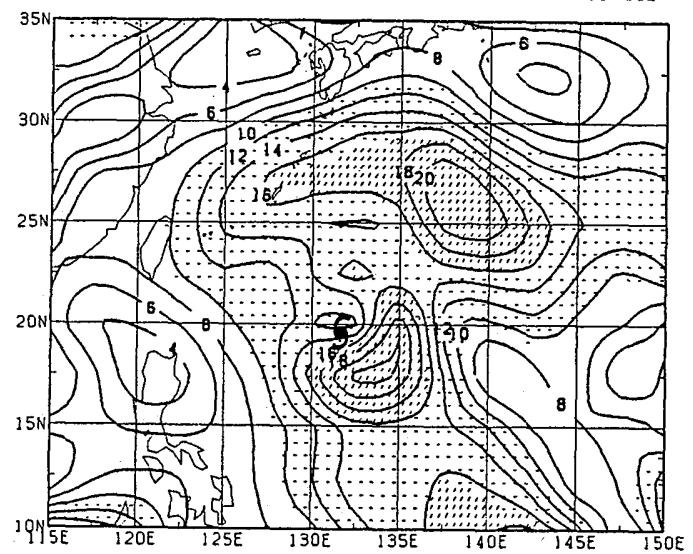

Fig. 9 The wind velocity field at 00UTC, 16 Aug. Areas of wind velocities stronger than $10 \mathrm{~ms}^{-1}$ are shaded.

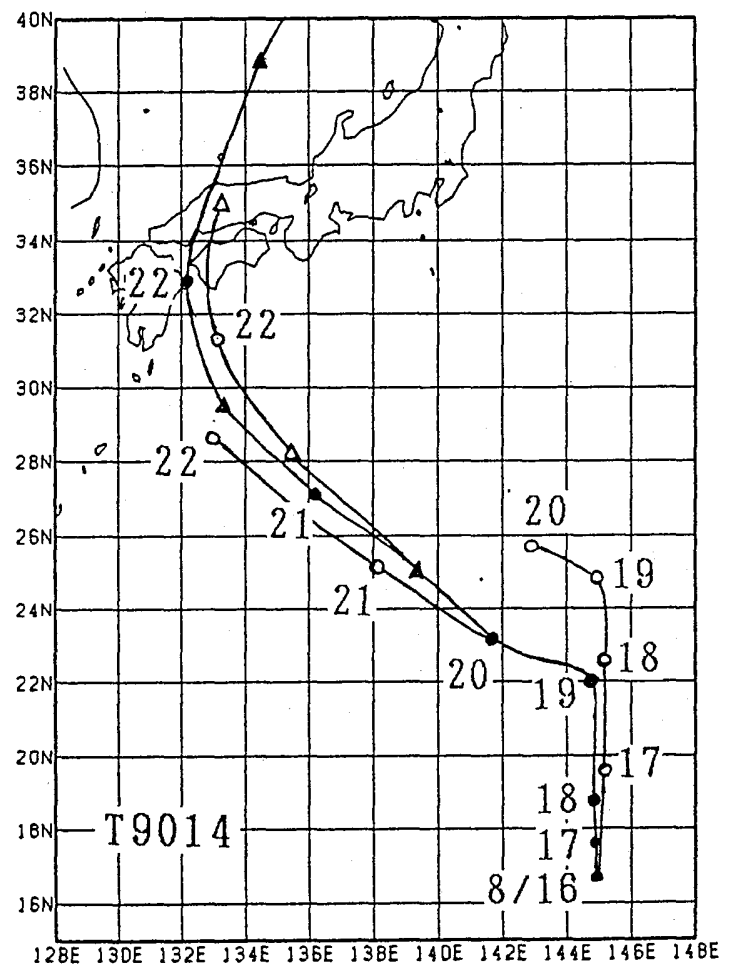

Fig. 10 Best track and predicted ones T9014 (including genesis stage). Initial time is 00UTC, Aug. 16 and 20, and 12UTC Aug. 20. The black and open triangles indicate the positions at $12 \mathrm{UTC}$. extended northwestward from Aug. 20 till Aug. 22. Fig. 11 shows the $700 \mathrm{mb}$ geopotential at 00UTC, Aug. 20 and 21. The extension of the subtropical high made the southerly flow stronger to the east of the typhoon. The prediction of such an extension of the subtropical high is not good enough to simulate the speed of the typhoon movement.

The slow and somewhat westward movement of the predicted typhoon for the initial data of 00UTC, Aug. 20 may be related to the initial distribution of the conditional instability, which is estimated from the difference between the moist static energy in the boundary layer and the saturated value at any level. The initial distribution estimated at $700 \mathrm{mb}$ is shown in Fig. 12. It is seen that the typhoon



Fig. 11 The $700 \mathrm{mb}$ geopotential height and wind fields at 00UTC, Aug. 20 and 21. T9012 is located to the west of T9014. 


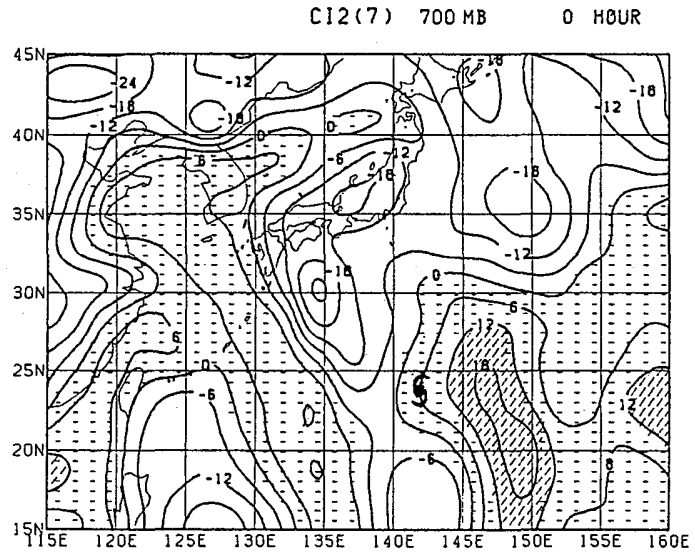

Fig. 12 The conditional instability field at the initial time (00UTC, 20 Aug.). The shaded areas indicate conditionally unstable area. The values are estimated as the difference between the moist static energy in the boundary layer and the saturated value at $700 \mathrm{mb}$ (unit : 0.1 $\left.\mathrm{cal} \cdot \mathrm{g}^{-1}\right)$. area is not so unstable, but the instability is very strong in an area at a distance of 500$1,000 \mathrm{~km}$ to the southeast of the typhoon center. This causes much convective activity in this area, which makes the southeasterly or southerly flow weaker just in the vicinity of the typhoon. When such strong conditional instability is reduced by making smaller the mixing ratio of water vapor in the boundary layer, the southerly flow to the east of the typhoon is simulated better, and therefore the predicted positions become much closer to the observed. The predicted position at 00UTC, 22 Aug. is $31.7 \mathrm{~N}, 134.1 \mathrm{E}$, which should be compared with $28.6 \mathrm{~N}, 132.9 \mathrm{E}$ obtained for unmodified instability.

Fig. 13 shows the result for T9015 (Abe). The 72-hour and 96-hour predictions are not bad for Aug. 26 and Aug. 27 data, respectively. Errors of the 72- and 96-hour predictions are about $200 \mathrm{~km}$ in these cases.

Fig. 14 shows the result for T9018 (Ed). Although the typhoon moved west-southwestward after Sept. 14, the predicted movement is

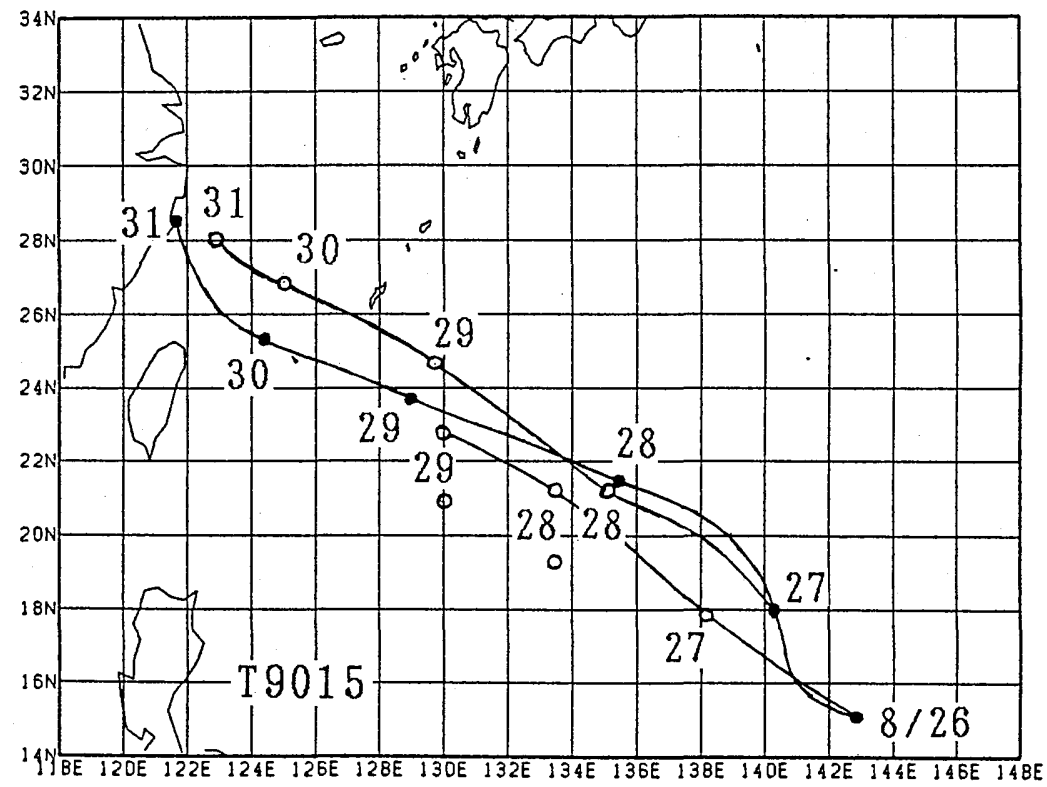

Fig. 13 Best track and predicted ones of T9015. Initial time is 00UTC, Aug. 26 and 27. 


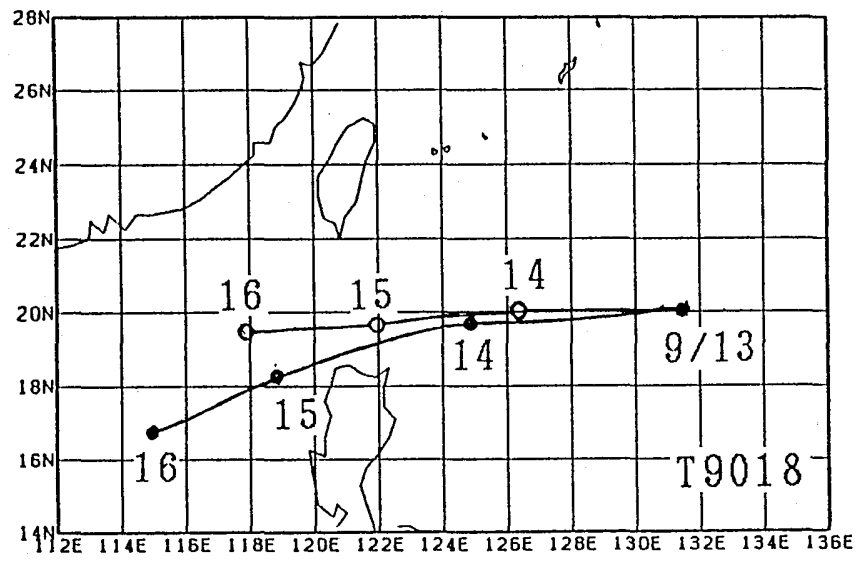

Fig. 14 Best track and predicted one of T9018. Initial time is 00UTC, Sept. 13.

almost westward and somewhat too slow. To the east of the typhoon (about $1,500 \mathrm{~km}$ ), T9019 was present (Fig. 15). The flow around T9018 is certainly affected by the existence of T9019, and therefore an improvement of prediction of the whole flow field is important to the west-southwestward movement of T9018.

Fig. 16 shows the result for T9019 (Flo) for the initial data of Sept. 13 and 14. For the Sept. 13 data, the 96 -hour prediction is not bad (position error of $250 \mathrm{~km}$ ), but the recurvature of the typhoon which took place afterwards is not simulated. This is also the case for the Sept. 14 data. The westward movement in the model is due to the formation of another typhoon, which did not take place in the actual atmosphere, but takes place to the east of T9019 in the model. The upper portion of Fig. 17 shows the $700 \mathrm{mb}$ geopotential at the initial time, when T9018 exists to the west of T9019. The lower figure shows the 72-hour predicted field. At this time T9018 is not seen in the fine-mesh area. The typhoon on the left is T9019. Another typhoon can be seen on the lower right portion of the figure. This was not observed in the actual situation. The formation of this false typhoon prevents a subtropical high from extending southward to the east of T9019, and therefore T9019 does not move toward higher latitudes but moves rather west-

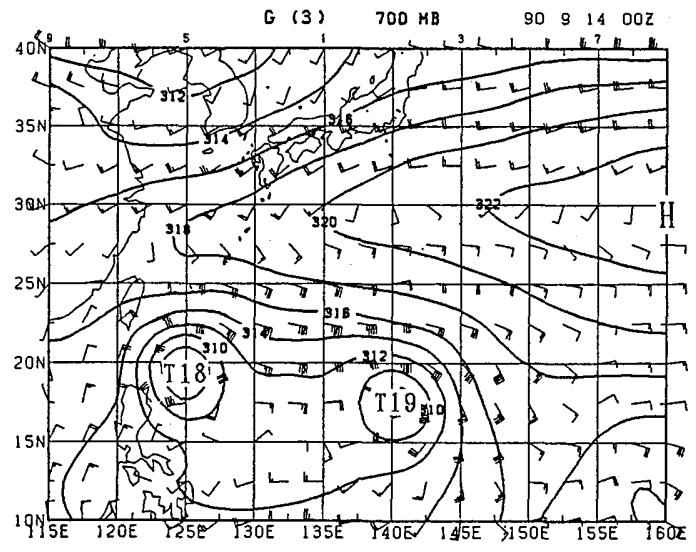

Fig. 15 The $700 \mathrm{mb}$ geopotential height and wind fields at 00UTC, Sept. 14. There exist two typhoons, T9018 (west) and T9019 (east).

ward, as in the case of T9018, by the effect of the easterly flow which exists to the north of the low pressure belt created by the two typhoons.

The formation of the false typhoon is related to the initial field of the conditional instability. According to the initial distribution of the conditional instability (Fig. 18), the typhoon area is not conditionally unstable and an area to the east of the typhoon is considerably unstable. The latter induces convective 
activity and the formation of the typhoon which did not take place in the actual atmosphere.

When the conditional instability is reduced by modifying the mixing ratio of water vapor in the boundary layer, the formation of the false typhoon is much delayed. Fig. 19 shows the 72-hour predicted field of the $700 \mathrm{mb}$ geopotential. A comparison with Fig. 17 shows that the predicted fields are very different. The subtropical high extends southward to the east of the typhoon, and the predicted typhoon continues to move northwestward, as shown by the dashed line in Fig. 16. (The northwestward movement is related to the initial wind field, as in the case of T9012.) The effect of modifying the initial conditional instability is very large. After 96 hours of the prediction (18 Aug.), the typhoon recurved northeastward, but the moving speed is very slow. This is due to the formation of a false typhoon, which is suggested from Fig. 19.

In many cases treated in this study, the typhoon area is not so much conditionally unstable or even stable at the initial time.
Relatively strong conditional instability is found rather in an area to the east of the typhoon area and to the south of the subtropical high. In this situation, very much convective activity takes place in the southern portion of the subtropical high in the present model. Although Fig. 18 is not accurate (because the present estimation of the conditional instability from the global analysis data is inevitably rough), the estimated field is probably qualitatively consistent with the data. Since the typhoon area is not very conditionally unstable initially, the predicted intensity of the typhoon is usually weak compared with the observed. As time integration goes on, however, the model creates conditional instability in the typhoon area because of sensible and latent heat supply from the sea surface owing to strong surface winds. It is found that use of larger mixing ratios of water vapor in the typhoon area does not have much effect on the predicted movement of typhoons. This should be contrasted with the large effects of the modification for a conditionally unstable area to the east of the typhoon.

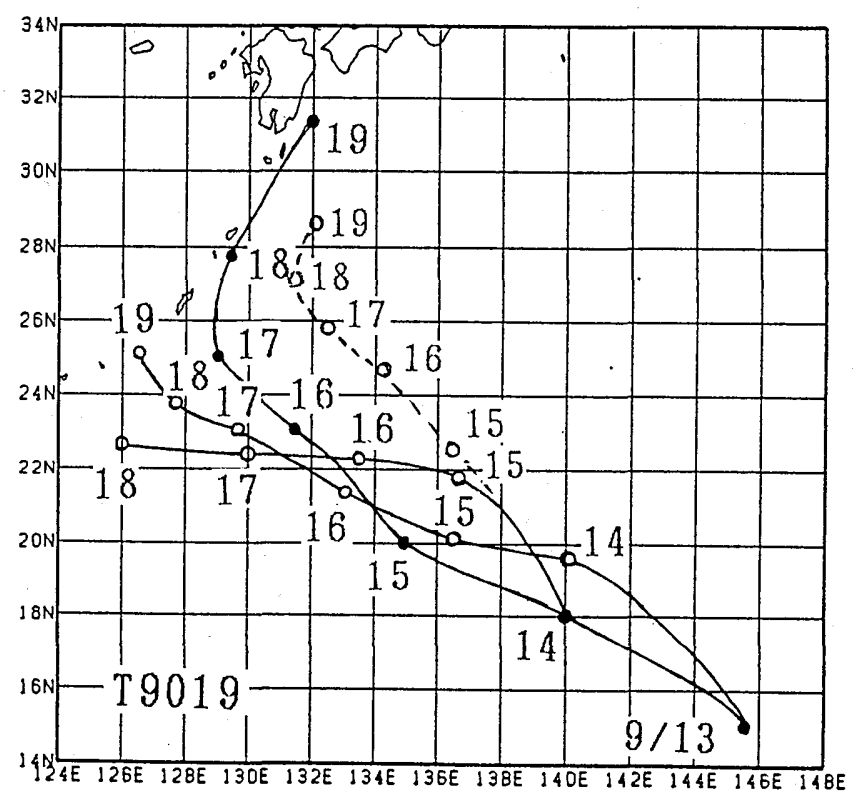

Fig. 16 Best track and predicted ones of T9019. Initial time is 00UTC, Sept. 13 and 14. 
G1(7) $700 \mathrm{~KB} \quad$ O HOUR
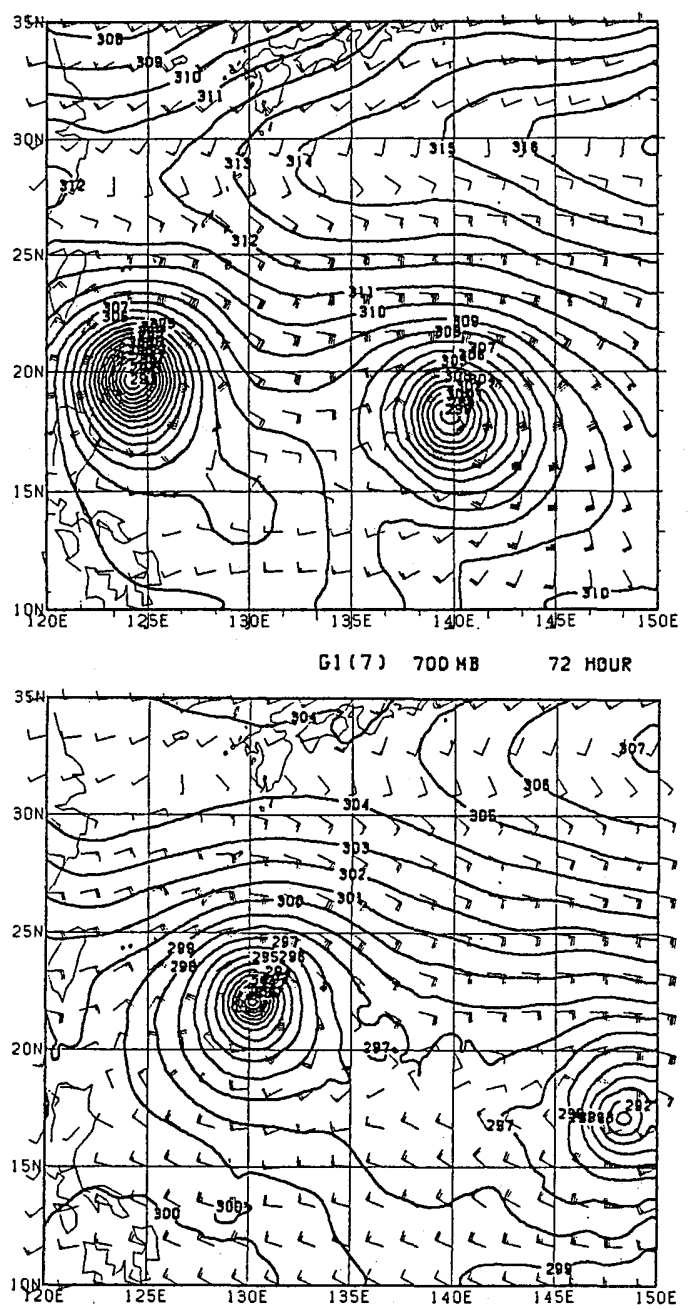

Fig. 17 The $700 \mathrm{mb}$ geopotential at the initial time (00UTC, 14 Sept.) and predicted field at 72 hours. Two typhoons T9018 (left) and T9019 (right) are seen in the upper figure. In the lower figure a typhoon which did not form in the actual atmosphere exists to the east of T9019.

Fig. 20 shows the result for T9019 for the initial data of Sept. 15, 16 and 17, respectively. The predicted tracks in these cases are in good agreement with the observed. However, the predicted speeds are somewhat either too fast or too slow. For example, for the initial data of 00UTC, Sept. 16 (right figure), the
C12(7) $700 \mathrm{MB} \quad 0$ HOUR

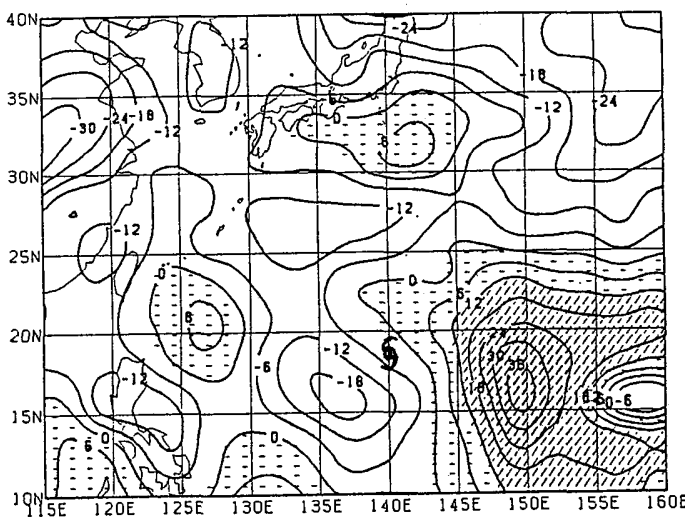

Fig. 18 The.conditional instability field at the initial time (00UTC, 14 Sept.).

G1(7) $700 \mathrm{HB} \quad 72$ HOUR

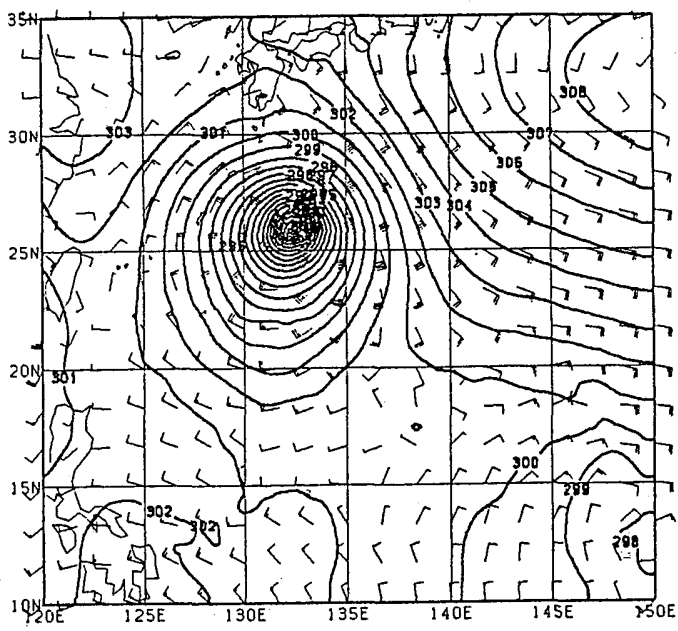

Fig. 19 Predicted $700 \mathrm{mb}$ geopotential at 72 hours for modified initial conditional instability field.

time of predicted landfall on the Kii peninsula is 01UTC, Sept. 19, whereas the observed one was 11UTC.

Fig. 21 shows the result for T9020 (Gene). The predicted movement is too fast for initial data of Sept. 25. A subtropical high extended westward to the north of the typhoon (Fig. 

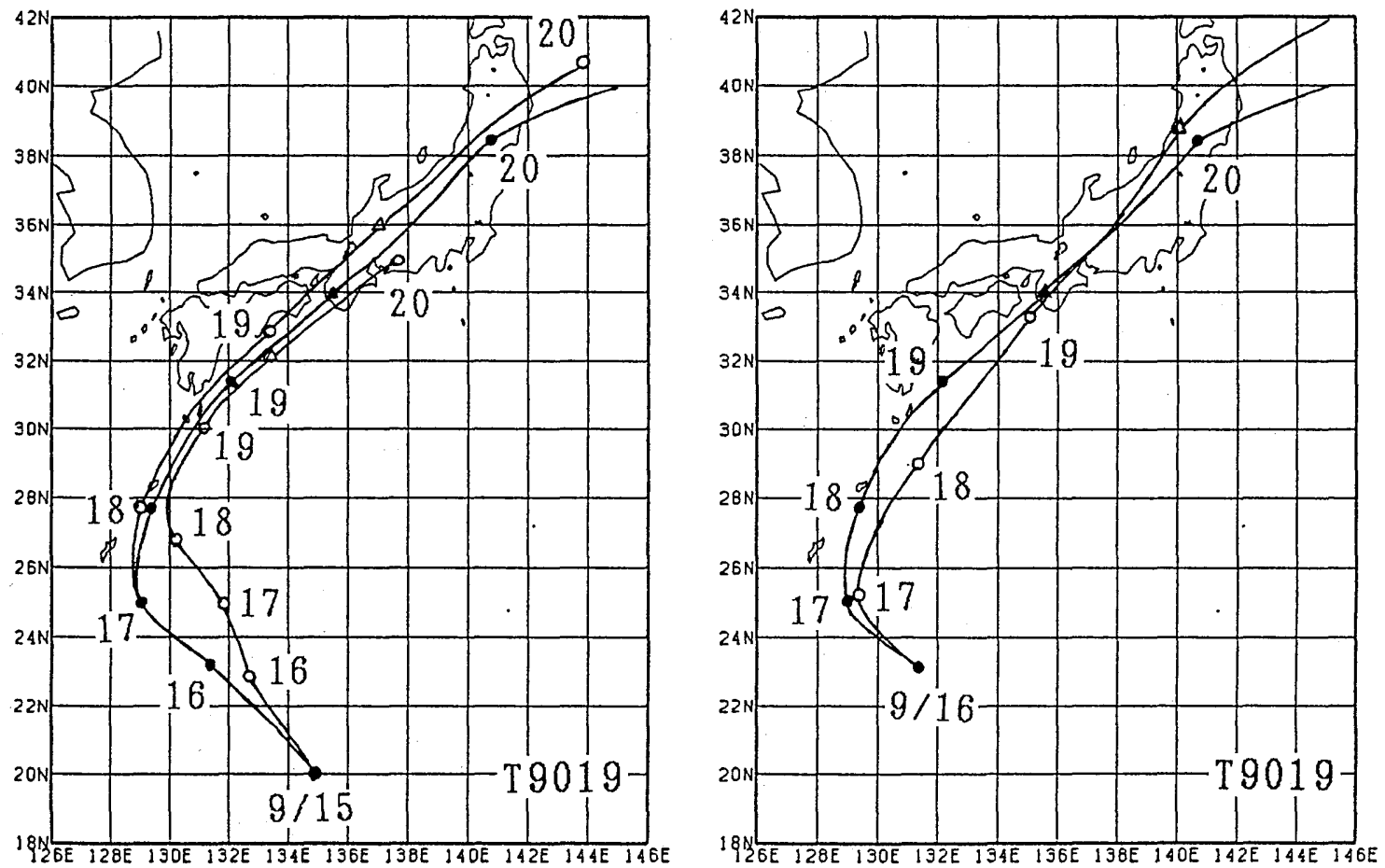

Fig. 20 Best track and predicted ones of T9019. Initial time is 00UTC, Sept. 15 and 17 (left) and Sept. 16 (right).

$22)$, which decelerated the typhoon movement on Sept. 26 and 27. This is not predicted well by the model.

\section{Concluding remarks}

This paper has described the model performance for the prediction of the motion of eight typhoons in August and September 1990 when SPECTRUM and TCM-90 were conducted. Although some of the predictions include large errors, the results are, on the whole, somewhat satisfactory in view of the present situation of the prediction accuracy. As for prediction errors, the numerical experiments suggest that the most important factors which cause prediction errors are poor prediction of the subtropical high and the inappropriate initial fields of environmental wind and conditional instability. The former may be related to the

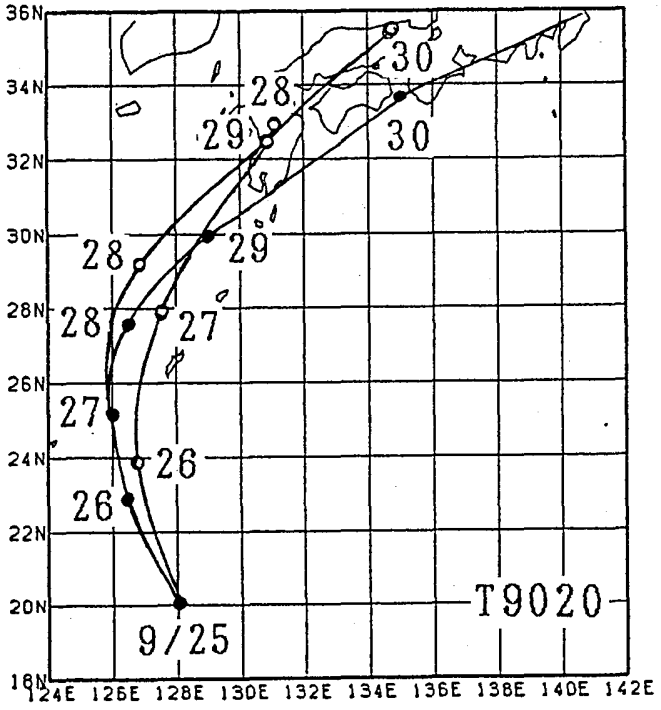

Fig. 21 Best track and predicted ones of T9020. Initial time is 00UTC, Sept. 25 and 27. 

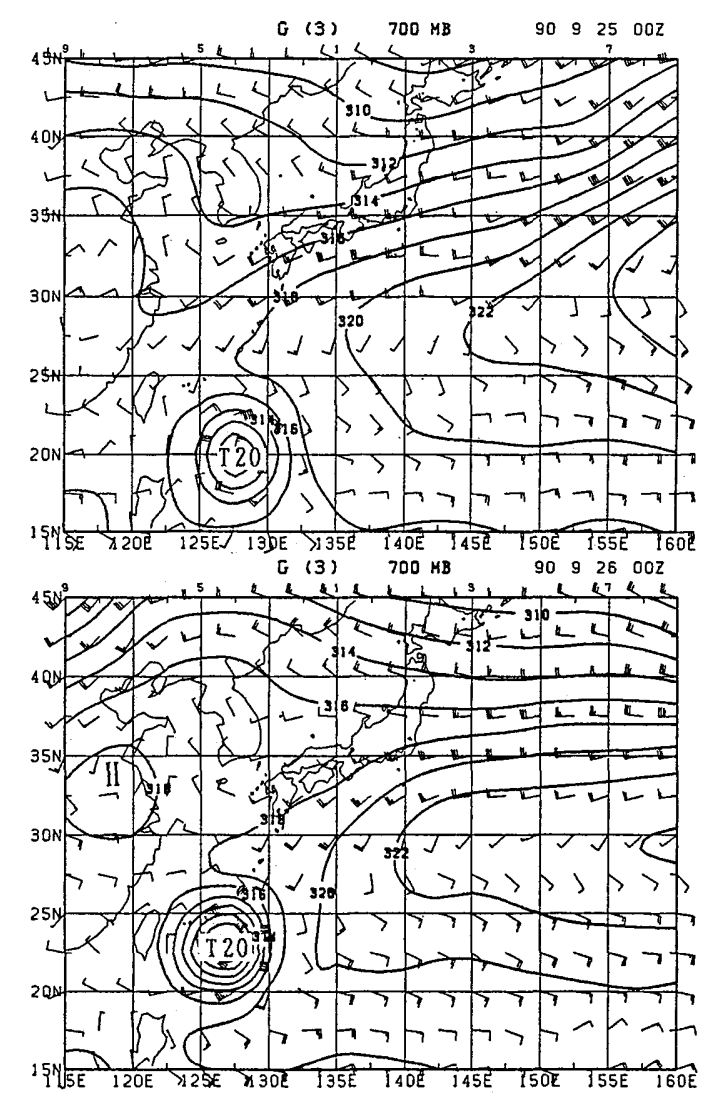

Fig. 22 The $700 \mathrm{mb}$ geopotential height and wind fields at 00UTC, Sept. 25 and 26.

large-scale initial field. As for the latter, it is necessary in some cases to modify the initial environmental wind field so that the typhoon motion during the early predicted period may be consistent with the observed motion. The initial field of conditional instability is also very important in that the predicted motion is greatly affected by the formation of another typhoon and convective activity in the surrounding area of the typhoon under consideration. Needless to say, the model itself should be responsible for prediction errors, and improvements on it are necessary, particularly with respect to the bahavior of the subtropical high.

The dependency of motion prediction on cumulus parameterization schemes, particularly the characteristics of the present model which includes rainwater prediction remain to be clarified in future studies. However, it may be important to remark the following points. As mentioned in section 1, the present model has been developed based on the author's past studies on the mechanism of tropical cyclones. Therefore; it is assumed that the model may also simulate tropical cyclone motion better. The use of such a model in the problem of tropical cyclone motion is one of the important features of this study, although further studies are necessary to clarify the characteristics of the model.

Acknowledgements :- The author is greatly indebted to Dr. M. Chiba of the Climate Research Department of the MRI for his help in this study. The author also wishes to thank the staff members of the MRI and the Numerical Prediction Division of the JMA for making the use of the global analysis data in this study possible. This study has been made as part of the five-year research plan 'Study on typhoon formation, movement and fine structure by numerical models'. The author wishes to thank the staff members of the Typhoon Research Department for their support for this study.

\section{References}

Elsberry, R. L., 1988 : ONR Tropical Cyclone Motion Research Initiative : Mid-year review, discussion and working group reports. Technical Report NPS 63-88-005, Naval Postgraduate School, Monterey, CA 93943, 103pp.

, B. C. Diehl, J. C.-L. Chan, P. A. Harr, G. J. Holland, M. Lander, T. Neta, and D. Thom, 1990 : ONR Tropical Cyclone Motion Research Initiative : field experiment summary. Technical Report NPS-MR-91-001, Naval Postgraduate School, Monterey, CA 93943, 107pp.

—, and R. F. Abbey, Jr., 1991 : Recent advances in understanding tropical cyclone motion. Technical Report NPS MR-91-003, Naval Postgraduate School, Monterey, CA 93943, 92pp.

Fiorino, M. and R. L. Elsberry, 1989a : Some aspects of vortex structure related to tropical cyclone motion. J. Atmos. Sci., 46, 975-990. and - $1989 \mathrm{~b}$ : Contributions to tropical cyclone motion by small, medium and large 
scales in the initial vortex. Mon. Wea.Rev., 117, 721-727.

Harrison, E. J., Jr ., 1981 : Initial results from the Navy two-way interactive nested tropical cyclone model. Mon. Wea. Rev., 109, 173177.

Harrison, E. J., Jr. and M. Fiorino, 1982 : A comprehensive test of the Navy nested tropical cyclone model. Mon. Wea. Rev., 110, 645 -650 .

Holland, G. J., 1983 : Tropical cyclone motion : Environmental interaction plus a beta effect. J. Atmos. Sci., 40, 328-342.

- 1984 : Tropical cyclone motion : A comparison of theory and observation. J. Atmos. Sci., 41, 68-75.

Iwasaki, T. and M. Ueno, 1991 : Typhoon prediction. A text for training of numerical prediction. Material (24), Numerical Prediction Division, 1-9 (in Japanese) .

Kamahori, H., 1991 : On the structure of wind of a tropical cyclone and its movement. Presented at the meeting of MSJ, Abstract No.59, p. 81 (in Japanese) .

Kurihara, Y. and M. A. Bender, 1980 : Use of a movable nested-mesh model for tracking a small vortex. Mon. Wea. Rev., 108, 17921809 .

— and - $1982:$ Structure and analysis of the eye of a numerically simulated tropical cyclone. J. Meteor. Soc. Japan, 60, 381-395.

Ley, G. W. and R. L. Elsberry, 1976 : Forecasts of Typhoon Irma using a nested-grid model. Mon. Wea. Rev., 104, 1154-1161.

Madala, R. V. and A.A. Piacsek, 1975 : Numerical simulation of asymmetric hurricane on a $\beta$-plane with vertical shear. Tellus, 27, 453468.

Mathur, M. B., 1974 : A multiple-grid primitive equation model to simulate the development of an asymmetric hurricane (Isbell, 1964). $J$. Atmos. Sci., 31, 371-393.

Ohnishi, H. , 1989 : A study on the tropical cyclone motion caused by its asymmetric structure. Collection of papers presented at the meeting of the Meteorological Research Institute, 3850 (in Japanese).

—, 1991 : Effect of the vortex structure on non- linear beta drift. Presented at the Technical Conference on SPECTRUM, November 1991.

— and M. Yamasaki, 1982 : A study of the motion of a cyclonic vortex on $\beta$-plane. Presented at the meeting of MSJ, Abstract No. 42, p.119 (in Japanese).

Ookochi, Y., 1974 : Numerical prediction of typhoon movement with use of multiple grid nesting. J. Meteor. Soc. Japan, 52, 387-390.

— 1978 : Preliminary test of typhoon Irma using a moving multiple-nested grid (MNG). $J$. Meteor. Soc. Japan, 56, 571-582.

Ueno, M., 1991a : Problems in typhoon prediction. Report of Numerical Prediction Division, 37, 104-122 (in Japanese).

— $1991 \mathrm{~b}$ : The current status of numerical weather prediction systems in Japan (4). Tenki, 38, 141-147 (in Japanese).

Shewchuk, J. D. and R. L. Elsberry, 1978 : Improvement of a baroclinic typhoon motion prediction system by adjustment of the initial wind field. Mon. Wea. Rev., 106, 713-718.

Yamasaki, M., 1983 : A further study of the tropical cyclone without parameterizing the effects of cumulus convection. Pap. Met. Geophys., $34,221-260$.

_- 1986 : A three-dimensional tropical cyclone model with parameterized cumulus convection. Pap. Met. Geophys., 37, 205-234.

—, 1987 : Parameterization of cumulus convection in a tropical cyclone model. Collection of Papers Presented at the WMO/IUGG NWP Symposium, Tokyo, 1986. T. Matsuno, Ed., Meteorological Society of Japan, 665678.

1989 : Numerical experiments of tropical cyclones under observed situations with a new scheme of implicit representation of cumulus convection. Extended abstracts, 18th Conference on Hurricanes and Tropical Meteorology, San Diego, May 1989, 172-173.

—, 1990 : Typhoon structure (and simulation of formation and numerical prediction model). Tenki, 37, 316-320 (in Japanese).

- and H. Ohnishi, 1985 : A study of tropical cyclone motion related to asymmetric structure. Presented at the meeting of MSJ, Abstract No. 47, p.37 (in Japanese). 


\section{雨水の予報を含む多重格子モデルを用いた台風の移動の研究}

\section{山岬正紀}

雨水や雲水を予報変数に含む多重 ( 3 重) 格子モデルを用いて台風の移動の数值実験を行った。対流のパラメ タリゼーションやモデルの主な部分は山岬（1986，1987）と同じであるが，ここでは緯度経度座標を用い，また 海陸分布や地形を考慮している。粗格子域は南緯 30 度より北を格子間隔 $15 / 4$ 度でおおい, 中間格子域は $5 / 4$ 度, 細格子域は $5 / 12$ 度を用いている。

数值実験では台風特別実験 (スペクトラム) が行われた 1990 年 8 月と 9 月の台風のうち 8 個の台風をとり扱っ た。初期条件は気象庁の全球客観解析デー夕を用いた。数值実験は約 20 例行ったが, 台風の移動の予測としては 概して良好な結果が得られている。予測誤差の主な原因としては，亜熱帯高気圧の振舞いをうまく予測できなか った場合が多く，また初期条件として与えた風の場や条件付不安定度の分布に関係していると考元れる場合も 多かった。 